\author{
Military Technical College \\ Kobry Elkobbah, Cairo, \\ Egypt.
}

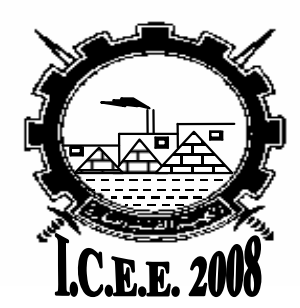

$4^{\text {th }}$ International Conference On

Chemical \& Environmental

Engineering

27-29 May 2008

\title{
FUTURE OF ENERGETIC MATERIALS: COMPETITION BETWEEN PERFORMANCE AND SAFETY
}

\author{
H. E. MOSTAFA*; M. M. ISMAIL*
}

\begin{abstract}
There is a further increasing of a parallel demand of improvements of performance and safety of explosives. Regarding the latter, in particular the fields of "safety of manufacture and handling", "chemical and ballistic stability / functionality", "toxicity", and "reduced vulnerability / sensitiveness" have to be respected. With propellants, performance is increased by different measures, including new formulations, burning rate moderation and increased loading density. Attention has to be paid to the improvement of stability and the replacement of toxic components. New formulations and production processes allow to markedly reduce the sensitiveness also for nitrocellulose-based propellants.

Primary explosives suffer from their extreme sensitiveness - new developments go towards primary explosive-free initiators, detonators or other initiation techniques (e.g. exploding bridge wire, exploding foil igniter, laser beam ignition). In case of main charge explosives, "new" substances with either improved performance or reduced sensitiveness become popular. Organic substances with high density, as many energetic groups as possible and additional internal energy by strongly strained molecular structure should offer a further
\end{abstract}

performance gain.

For pyrotechnics, only marginal improvements appear to be possible with conventional micro particles, whereas nanotechnology seems to be able to double the performance of certain pyrotechnics and, at the same time, to increase the safety level by a factor of ten.

On the way of safety improvement, some techniques were used for hazard assessment for different types of explosives in many applications (e.g. GAP test and cook off test). GAP test is definitively a very practical tool to define the sensitivity, or better describe the initiability of reactive materials by shock loads. Cook-off test is a complex and costly hazard that has an impact over a broad range of disciplines; munitions design, testing, transportation, and storage, as well as fire fighting tactics.

It is not practical to generate data describing ordnance response with respect to the shipboard fire threat for every ordnance item loaded. Ship commanders require accurate answers to a number of fire-related questions

\footnotetext{
* Egyptian Armed Forces
} 